\title{
Micropuncture Study of Nephron
}

\section{Function in the Rhesus Monkey}

\author{
Cleaves M. Bennett, Barry M. Brenner, and \\ Robert W. Berliner with the technical assistance of Julia L. Troy \\ From the Laboratory of Kidney and Electrolyte Metabolism, National \\ Heart Institute, National Institutes of Health, Bethesda, Maryland
}

A в S T R A C T The function of the proximal and distal tubule was studied in the rhesus monkey during antidiuresis and during the diuresis after furosemide administration (during which extracellular fluid volume was maintained).

In the proximal tubule, fluid to plasma ratios for sodium, potassium, and osmolality approximated unity. During antidiuresis, about $30 \%$ of the filtered water remained at the end of the accessible portion of this segment (92\% of length). Fluid was hypotonic to plasma throughout the distal tubule. $25 \%$ of the filtered water was present in the early distal tubule. Small but significant water reabsorption (about $8 \%$ of filtered) occurred in the remainder of this segment. Tubule fluid to plasma potassium concentration ratios tended to increase along the distal tubule, and the amount of potassium, relative to the amount filtered, increased from $13 \%$ in the early portion of this segment to $26 \%$ in the late portion.

After furosemide was administered animals excreted about one-third of the filtered sodium and water. Despite this diuresis, electrolyte and water reabsorption along the proximal tubule did not differ from values obtained in control

An abstract of this work appears in J. Clin. Invest. 1967. $46: 1035$. Complete tables of data from these experiments are available from the American Documentation Institute, 2000 P Street, N. W., Washington, D. C. 20036.

Address requests for reprints to Dr. C. M. Bennett, Laboratory of Kidney and Electrolyte Metabolism; National Heart Institute, Bethesda, Md. 20014.

Dr. Brenner is a Postdoctoral Research Fellow, National Heart Institute.

Received for publication 18 July 1967 and in revised form 15 September 1967. animals. Osmolality and sodium concentration of fluid from the distal tubule approached those of plasma. 22\% of the filtered sodium (twice the control values) reached the distal tubule, whereas the fraction of filtered water remaining was only slightly increased. These findings indicate that, after the administration of this drug, inhibition of sodium reabsorption occurred in the water-impermeable segment of the nephron, rather than in the proximal tubule. After furosemide administration, all tubule fluid to plasma potassium concentration ratios in the distal tubule were equal to or greater than one, suggesting inhibition of active potassium reabsorption at or prior to this site.

Fluid to plasma bicarbonate concentration ratios from the midportion of the proximal tubule were consistently less than one in normal monkeys. After acetazolamide was administered, the bicarbonate concentration of samples of tubule fluid recollected from these same sites was the same as, or higher than in plasma. This fact demonstrates the inhibition of bicarbonate reabsorption in this portion of the tubule.

\section{INTRODUCTION}

It is likely that many of the basic transport processes operative in renal tubule cells are similar in rat, dog, and man. Indeed, micropuncture studies in the dog and rat have revealed that individual nephron function in these species is quite similar $(1,2)$. Those differences which have been found are primarily of a quantitative nature and are not necessarily fundamental. It has been found, however, that the extent of sodium, water, and bi- 
TABLE I

Summary of Mean Values of Glomerular Filtration Rates (GFR), Fractional WVater, Sodium and

\begin{tabular}{cccc}
\hline $\begin{array}{c}\text { Experimental } \\
\text { condition }\end{array}$ & GFR & $\begin{array}{c}(\mathrm{U} / \mathrm{P}) \\
\text { osmolality }\end{array}$ & $\begin{array}{c}(\mathrm{P} / \mathrm{L}) \\
\text { inulin }\end{array}$ \\
\hline Hydropenia & $\begin{array}{c}\text { ml/min per } k g^{*} \\
1.45 \pm 0.23 \ddagger \\
\end{array}$ & $(62) \S$ & $2.66 \pm 0.39$ \\
$(33)$ & $0.45 \% \pm 0.09$ \\
Furosemide & $1.50 \pm 0.39$ & $0.94 \pm 0.03$ & $(61)$ \\
& $(30)$ & $(27)$ & $32.5 \% \pm 4.24$ \\
\end{tabular}

* Experimental kidney only. $\ddagger$ Values represent mean \pm one standard deviation. $\$$ Numbers in pirentheses

carbonate reabsorption in the proximal tubule, and sodium and water reabsorption and potassium addition in the distal tubule are different in dog and rat. It is not possible to be certain whether these differences are inherent characteristics of these species or represent differences in methodology. Nevertheless, they serve to emphasize that extrapolation of data obtained in one species to another species must be done with caution.

There are few studies of renal function in primates other than man, primarily because it is easy to perform clearance experiments in man. However, clearances do not accurately measure function at all sites along the nephron, particularly in the more proximal portions (3). Accordingly, in the present investigation the functions of the proximal and distal tubule in the rhesus monkey have been studied using the micropuncture technique both under conditions of normal antidiuresis and after the administration of furosemide and acetazolamide. To the extent that nephron function in the monkey can be assumed to be more representative of nephron function in other primates, the results of these studies are likely to be more pertinent to the interpretation of the more indirect measurements of renal function in man. In addition, since these studies indicate that micropuncture of the monkey nephron is feasible, this animal may be a useful model for evaluating the pathophysiology of renal disorders and the mechanism of action of diuretic drugs in relation to man.

\section{METHODS}

\section{General procedure}

Studies were performed on young male and female rhesus monkeys (Macaca mulatta) weighing $2.7-6.0 \mathrm{~kg}$. All monkeys were fed a balanced diet of Purina dry monkey chow supplemented with fresh fruit, and they all were allowed free access to water. They were de- prived of food but not water for 18-24 hr prior to study in order to reduce the volume of abdominal contents at the time of micropuncture.

The animals were anesthetized rapidly by an intravenous injection of $20 \mathrm{mg} / \mathrm{kg}$ sodium pentobarbital and were given small supplemental doses as necessary. Tracheotomy was performed in all experiments. Indwelling polyethylene catheters were inserted into a femoral vein to administer fluid, inulin, and drugs, into a femoral artery for periodic samplings of blood and estimation of arterial blood pressure, and into the left common carotid artery to the level of the aortic arch in order to inject lissamine green. The right ureter was exposed and catheterized through a suprapubic incision. The right kidney served as the control side in all experiments.

The left kidney was exposed through a flank incision, gently dissected free of its perirenal and peritoneal attachments, and its ureter cannulated within $2 \mathrm{~cm}$ of its origin. The animal was placed on a heated pad atop a micropuncture table, and the abdominal wound was exposed by means of retraction sutures and a bulk welge inserted under the right flank. The kidney was then suspended in a malleable metal holder so that it would be snugly encased, thereby reducing pulse and respiratory motion. A $1 \mathrm{~cm}^{2}$ portion of renal capsule was removed, the area illuminated by a quart\% rod, and the exposed surface continuously bathed with mincral oil heated to $37^{\circ} \mathrm{C}$.

Samples from proximal and distal tubules were obtained using standard collection techniques. The rate of collection was adjusted to keep a short column of oil stationary just distal to the puncture site. Distal tubules could be identified on the surface by their relative transparency, small size, and straight course. Occasionally their iclentification necessitated the intra-arterial injection of $0.25 \mathrm{cc}$ of $8-10 \%$ lissamine green; appearance time was approximately $20-35 \mathrm{sec}$ after the rapid dye injection. In most instances, 15-20 nliter of fluid was obtained for analysis. After the fluid was collected, puncture sites were localized by means of microdissection.

Sharpened micropipettes with external tip diameters of 8-12 $\mu$ were prepared as previously described (4). All micropipettes were externally coated with silicone (Siliclad, Clay-Adams, Inc., New York), filled just prior to use with low viscosity Kel-F oil (Minnesota Mining \& Mfg. Co.), and colored with Surlan black. 
TABLE I (Concluded)

Potassium Excretion, and Plasma Composition during Hydropenia and Furosemide Diuresis

\begin{tabular}{|c|c|c|c|}
\hline$\frac{(\mathrm{U} / \mathrm{P}) \mathrm{Na}}{(\overline{\mathrm{U}} / \mathrm{P}) \mathrm{In}} \times 1(0)$ & $\frac{(\mathrm{U} / \mathrm{P}) \mathrm{K}}{(\mathrm{U} / \mathrm{P}) \mathrm{In}} \times 100$ & $\begin{array}{l}\text { Plasma } \\
\text { sodium }\end{array}$ & $\begin{array}{c}\text { Plasma } \\
\text { potassium }\end{array}$ \\
\hline & \multicolumn{3}{|c|}{$m E q / l i l e r$} \\
\hline $\begin{array}{c}0.08 \% \pm 0.07 \\
(46)\end{array}$ & $\begin{array}{c}22.8 \% \pm 6.6 \\
(46)\end{array}$ & $\begin{array}{c}143 \pm 2.5 \\
(60)\end{array}$ & $\begin{array}{c}3.2 \pm 0.23 \\
(60)\end{array}$ \\
\hline $\begin{array}{c}28.5 \% \pm 4.66 \\
\text { (20) }\end{array}$ & $\begin{array}{c}81.6 \% \pm 14.4 \\
(20)\end{array}$ & $\begin{array}{c}149 \pm 4.6 \\
(30)\end{array}$ & $\begin{array}{c}2.5 \pm 0.57 \\
(30)\end{array}$ \\
\hline
\end{tabular}

indicate number of observations.

In all studies, after an equilibration period of at least $30 \mathrm{~min}$ following the injection of priming and sustaining inulin infusions, $15-20$ min clearance periods were obtained. Samples of arterial blood were drawn at the midpoint of each period, while urine from each ureteral catheter was allowed to empty under oil into volumetric containers.

Three experimental protocols were employed:

Control antidiuresis. 11 monkeys were prepared for micropuncture and infused with $12.0-22.5 \mathrm{ml}$ of $0.9 \%$ $\mathrm{NaCl} / \mathrm{hr}$. While no attempt was made either to restrict oral fluid intake prior to study or to administer exogenous vasopressin, all animals in this group were in antidiuresis. In nine animals from this group, samples from both proximal and distal tubules were obtained; in two animals only distal samples were obtained.

Furosemide diuresis. Five antidiuretic animals were infused with $0.9 \% \mathrm{NaCl}$ at a rate of $22.5 \mathrm{ml} / \mathrm{hr}$ for approximately $1 \mathrm{hr}$ prior to micropuncture. During this time two or three control clearance periods were obtained. Furosemide (3-5 $\mathrm{mg} / \mathrm{kg}$ ) was given intravenously as a prime, and the same dose was administered per hour. The animals incurred a fluid deficit of $25-50 \mathrm{ml}$. Thereafter, extracellular fluid volume was maintained at this level by the infusion of $0.9 \% \mathrm{NaCl}$ at a rate, estimated at frequent intervals, equal to the rate of urine flow.

Control antidiurcsis-bicarbonatc mcasurements. In four antidiuretic animals, proximal tubule bicarbonate concentration was measured using quinhydrone microelectrodes. After control collections were made, three of these animals were given a single intravenous injection of acetazolamide $(20 \mathrm{mg} / \mathrm{kg})$, and samples were recollected from the previous puncture sites for repeat measurement of bicarbonate concentration. The rise in urine flow rate was modest after the administration of acetazolamide, and volume replacement was therefore unnecessary.

\section{Analytical methods}

The osmolality of tubule fluid, plasma, and most urine samples was determined microcryoscopically by the technique of Ramsay and Brown (5). When urine volumes were adequate, osmolality was measured with an Aminco-Bowman osmometer. ${ }^{1}$ Sodium and potassium

\footnotetext{
${ }^{1}$ American Instrument Co., Inc., Silver Spring, Md.
}

concentrations in tubule fluid were measured simultaneously and in duplicate by the method of Vurek and Bowman (6) using a dual channel helium-glow ultramicrophotometer. Sodium and potassium concentrations in plasma and urine were determined with an internal standard flame photometer. ${ }^{2}$

Inulin concentration in tubule fluid was measured by the fluorophotometric method of Vurek and Pegram (7), modified to increase the hydrolysis reaction time at $100^{\circ} \mathrm{C}$ to $10 \mathrm{~min}$. Inulin concentration in plasma and urine was determined by the anthrone method of Führ, Kaczmarczyk, and Krüttgen (8).

Quinhydrone microelectrodes, similar in design to those described by Pierce and Montgomery (9), were used to estimate tubule fluid bicarbonate concentration. In place of mercury, however, each electrode was filled with mineral oil which had been equilibrated with $5 \%$ $\mathrm{CO}_{2}$ immediately prior to use. Approximately 10 nliter or less of proximal tubule fluid or a similar volume of freshly prepared bicarbonate solution, preequilibrated with $5 \% \mathrm{CO}_{2}$, was aspirated directly into the microelectrode and the electrode tip sealed with egg albumen. A Cary vibrating reed electrometer was used to determine the potential difference between the quinhydrone microelectrode and a calomel half-cell; both were immersed in a saturated solution of $\mathrm{KCl}$ previously equilibrated with $5 \% \quad \mathrm{CO}_{2}$ and maintained at $37^{\circ} \mathrm{C}$. The $\mathrm{pH}$ of the samples can be calculated from the Pierce-Montgomery equation:

$$
\mathrm{pH}=\frac{\text { Eqh-Ecal-emf }}{0.0001982 T}
$$

where Eqh and Ecal represent the standard potentials for the quinhydrone and $\mathrm{KCl}$-calomel electrodes respectively, and $T=$ absolute temperature. Bicarbonate concentration in tubule fluid samples was determined from a standard curve derived from the relationship between the $\log \left(\mathrm{HCO}_{3}\right)$ and the measured emf. Arterial blood and urine, collected anaerobically, were analyzed for $\mathrm{pH}$ at $37^{\circ} \mathrm{C}$ in a Beckman model $76 \mathrm{pH}$ meter. Plasma $\mathrm{CO}_{2}$ content was determined manometrically with a Natelson microgasometer.

${ }^{2}$ Model DB-5, Baird-Atomic, Inc., Cambridge, Mass. 
TABLE II

Measurements of Length of Nephron Segments

\begin{tabular}{|c|c|c|c|c|}
\hline Species & Reference & Proximal tubule & Loop of Henle & Distal tubule \\
\hline Rat & $\begin{array}{l}(11) \\
(12)\end{array}$ & $\begin{array}{c}m m \\
{[9.0-13.5]^{*}} \\
10.0 \pm 0.3 \ddagger\end{array}$ & $\begin{array}{c}m m \\
{[5.0-7.3]}\end{array}$ & $\begin{array}{c}m m \\
{[2.5-2.7]} \\
1.4[0.9-1.6]\end{array}$ \\
\hline \multirow[t]{2}{*}{ Dog } & (13) & $\begin{array}{c}15.1 \pm 3.3 \\
{[9.0-24.0]}\end{array}$ & & \\
\hline & (12) & $\begin{array}{c}14.8 \\
{[12.8-16.5]}\end{array}$ & {$[5.2-15.0] \S$} & {$[3.0-3.9]$} \\
\hline Rhesus monkey\|l & This study & $\begin{array}{c}6.4 \pm 1.5 \\
{[3.6-9.6]}\end{array}$ & $\begin{array}{l}1.4 \pm 0.3 \S \\
{[0.9-1.9] \S}\end{array}$ & $\begin{array}{l}3.1 \pm 1.0 \\
{[1.4-6.6]}\end{array}$ \\
\hline Man & (14) & {$[7.2-23.1]$} & {$[0-5.6] \S$} & [1.6-4.2] \\
\hline
\end{tabular}

* Numbers in brackets represent the range of measurements.

$\ddagger$ Unbracketed values represent the mean \pm one standard deviation.

$\S$ Represents measurements of the descending limb only.

|| Note that the rhesus monkeys used in these studies were immature animals, whereas the other species studied were adult animals.

\section{RESULTS}

\section{Control antidiuresis}

Values of glomerular filtration rate (GFR) are shown in Table I. A mean GFR of $1.45 \mathrm{ml} / \mathrm{min}$ per $\mathrm{kg}( \pm 0.23 \mathrm{SD})$ was observed on the experimental side compared to a mean value of $1.70 \mathrm{ml} /$ min per $\mathrm{kg}( \pm 0.29 \mathrm{sD})$ on the control side. These filtration rates closely agree with values previously reported for monkeys and other small primates in the unanesthetized state (10).

Tubule dissection. 100 superficial proximal or distal tubules with attached loops of Henle were dissected. Measurements of the length of these segments are shown in Table II, along with comparative measurements from other species (11-14).
In every instance, the loop was short and confined to the cortex. Nephrons with long loops extending into the medulla were always associated with juxtamedullary glomeruli and were not accessible to micropuncture.

Often the proximal tubule remained on the surface for most of its length, so that a greater percentage of its total length was accessible to puncture than in the rat and dog. Samples were obtained from sites in the proximal tubule ranging from 12 to $92 \%$ of its total length.

After the intra-arterial injection of lissamine green, many distal tubules could be seen on the surface of the kidney. Occasionally the junction of two distal tubules could be seen. The cortical collecting ducts so formed always coursed beneath the

TABLE III

Summary of Mean Osmolality, Sodium and Potassium Concentration Ratios for the Proximal Convoluted Tubule during Control Antidiuresis and Furosemide Diuresis

\begin{tabular}{|c|c|c|c|c|c|c|}
\hline & \multicolumn{2}{|c|}{$(\mathrm{TF} / \mathrm{P})_{\mathrm{osm}}$} & \multicolumn{2}{|c|}{$(\mathrm{TF} / \mathrm{P})_{\mathrm{Na}}$} & \multicolumn{2}{|c|}{$(\mathrm{TF} / \mathrm{P})_{\mathbf{R}}$} \\
\hline & $\begin{array}{c}\text { Control } \\
\text { antidiuresis }\end{array}$ & Furosemide & $\begin{array}{c}\text { Control } \\
\text { antidiuresis }\end{array}$ & Furosemide & $\begin{array}{c}\text { Control } \\
\text { antidiuresis }\end{array}$ & Furosemide \\
\hline Mean & 0.98 & 1.01 & 1.03 & 1.00 & 1.04 & 0.99 \\
\hline SD & \pm 0.02 & \pm 0.03 & \pm 0.05 & \pm 0.03 & \pm 0.03 & \pm 0.21 \\
\hline No. samples & 17 & 20 & 20 & 14 & 21 & 14 \\
\hline No. animals & 6 & 5 & 6 & 4 & 6 & 4 \\
\hline
\end{tabular}


TABLE IV

Summary of Mean Osmolality, Sodium and Inulin Concentration Ratios for the Distal Convoluted Tubule during Control Antidiuresis and Furosemide Diuresis

\begin{tabular}{|c|c|c|c|c|c|c|}
\hline & \multicolumn{2}{|c|}{$(\mathrm{TF} / \mathrm{P})_{\text {osm }}$} & \multicolumn{2}{|c|}{$(\mathrm{TF} / \mathrm{P})_{\mathrm{Na}}$} & \multicolumn{2}{|c|}{$(\mathrm{P} / \mathrm{TF})_{\text {In }}($ early D.T.)* } \\
\hline & $\begin{array}{c}\text { Control } \\
\text { antidiuresis }\end{array}$ & Furosemide & $\begin{array}{c}\text { Control } \\
\text { antidiuresis }\end{array}$ & Furosemide & $\begin{array}{c}\text { Control } \\
\text { antidiuresis }\end{array}$ & Furosemide \\
\hline Mean & 0.50 & 0.89 & 0.43 & 0.85 & 0.25 & 0.29 \\
\hline SD & \pm 0.16 & \pm 0.06 & \pm 0.15 & \pm 0.08 & \pm 0.04 & \pm 0.05 \\
\hline No. samples & 29 & 11 & 31 & 11 & 13 & 6 \\
\hline No. animals & 8 & 5 & 8 & 4 & 7 & 2 \\
\hline
\end{tabular}

${ }^{*}$ Represents samples obtained from 24 to $49 \%$ of the distal convoluted tubule (D.T.)

surface tubules immediately, and thus they were not accessible to micropuncture.

Osmolality. The tubule fluid to plasma (TF/P) osmolality ratios of 17 samples from proximal tubules in six animals are shown in Table III and are plotted on a $\log$ scale as a function of puncture site in Fig. 1A. It can be seen that fluid collected from the proximal nephron was isosmotic with plasma (mean plasma milliosmolality $=307.5$; range $=296-327$ ). In contrast, samples from the distal tubule (Table IV and Fig. 1A) were always hypotonic to plasma and remained unchanged throughout the accessible length of this nephron segment (the slope was not significantly different from zero, as shown in Table V). ${ }^{8}$ The final urine to plasma osmolality ratio during these studies averaged $2.66 \pm 0.29$ SD.

Water reabsorption. The data from control monkeys are shown in Fig. 2A. Approximately one-third of the filtered volume remained at the end of the accessible portion of the proximal tubule. The slope of the line representing the relationship between the fraction of filtered water remaining $[(\mathrm{P} / \mathrm{TF})$ inulin], and puncture site in this segment of the nephron is $-0.00559 \pm$ $0.00094 \mathrm{SE}$, and its intercept is at $y=0.995 .{ }^{4}$

8 The logs of the (TF/P) ratios (osmolality, sodium, and potassium) or of the clearance ratios (water, sodium, and potassium) were related to the location of the puncture site in the distal tubule (expressed as a percentage of its total length) using the method of least squares (15). For each relationship the slope and its standard error were calculated, and the significance of the relationship was determined using the Student's $t$ test, where $t=$ slope $/ \mathrm{sE}$.

4 The theoretical intercept on the $y$ axis is at 1.0 , since the concentration of inulin in the glomerular filtrate must equal the concentration of inulin in the plasma.
Significant net reabsorption of water was not observed in the short pars recta of the proximal tubule, in the loop of Henle, and in the inaccessible early segment of the distal tubule (Fig. 2A). Beyond this point in the distal tubule, small but statistically significant reabsorption of water was observed. The slope of the regression line for these data is given in Table $\mathrm{V}$ and corresponds to reab-

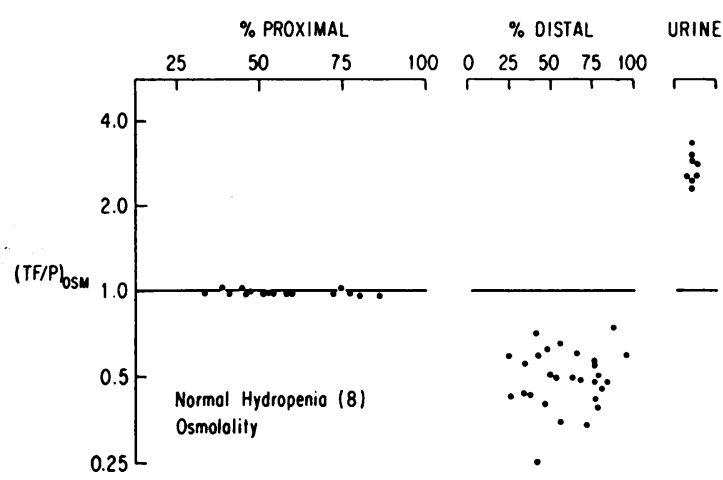

Figure 1A Tubule fluid to plasma (TF/P) and urine to plasma (U/P) osmolality ratios during hydropenia. In this and subsequent figures, the number in parentheses refers to the number of animals, and the urine values represent mean values for each animal.

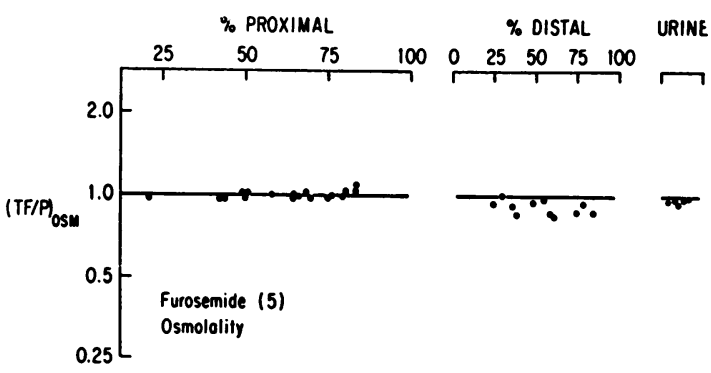

FIgURE $1 B \quad T F / P$ and $U / P$ osmolality ratios during furosemide diuresis. 


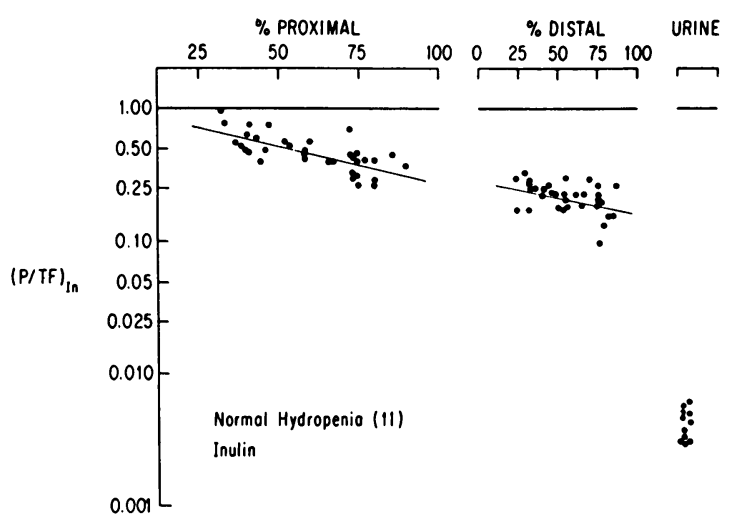

FIgURe 2A Plasma to tubule fluid (P/TF) and plasma to urine $(P / U)$ inulin concentration ratios during hydropenia. The lines represent the slopes relating the fraction of filtered water remaining $[(\mathrm{P} / \mathrm{TF})$ Inulin], and the puncture site.

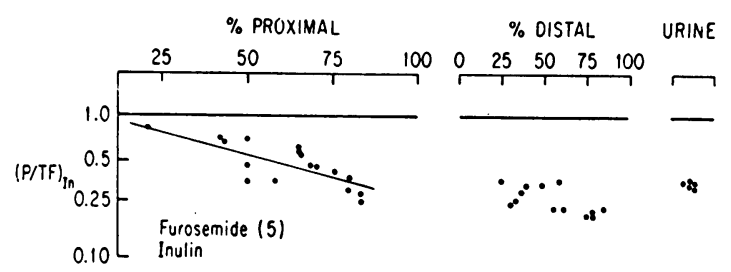

Figure 2B $\mathrm{P} / \mathrm{TF}$ and $\mathrm{P} / \mathrm{U}$ inulin concentration ratios during furosemide diuresis. No slope is given for the distal tubule because data from the early and late portions of this segment were obtained from different animals.

sorption of approximately $8 \%$ of the glomerular filtrate, or about one-third of the volume delivered to the earliest accessible portion of this segment. The $95 \%$ confidence limits for the slope of this line indicate that between 1 and $13 \%$ of the filtrate was reabsorbed. It can be seen in Fig. 2A that nearly all of the remaining $20 \%$ of the filtered volume that enters the collecting ducts is reabsorbed.

Sodium reabsorption. The results of measurement of $(\mathrm{TF} / \mathrm{P})$ sodium concentration ratios in 20 proximal samples and 31 distal samples from eight animals are shown in Tables III and IV and in the upper portion of Fig. 3A. It can be seen that the $\mathrm{TF} / \mathrm{P}$ ratios in the proximal tubule approximated unity. In contrast, in the distal tubule, fluid to plasma concentration ratios were all well below unity. The slope of the regression line for the relationship between the $(\mathrm{TF} / \mathrm{P})_{\mathrm{Na}}$ and the puncture site is not significantly different from zero, indicating no change in this variable along the distal tubule (Table V). Assuming that chloride is the predominant accompanying anion, sodium chloride accounted for about $75 \%$ of the osmolality.

The lower portion of Fig. 3A, which illustrates fractional ${ }^{5}$ sodium reabsorption, shows that approximately $35 \%$ of the filtered sodium is present at the end of the proximal tubule. Approximately $10 \%$ of filtered sodium reached the earliest accessible portion of the distal tubule. This value is less than half of the fraction of filtered water remaining at the same site, which indicates that sodium was reabsorbed in hypertonic proportions by the relatively water-impermeable ascending limb. Significant net reabsorption of sodium along the remainder of the distal tubule could not be detected $(0.1<P<0.2)$, as shown in Table V. Nearly all of the remaining sodium was reabsorbed in the collecting duct system since fractional sodium excretion was extremely low in these studies (less than $0.1 \%$ ).

Potassium reabsorption. Data obtained from 21 proximal and 30 distal tubules during antidiuresis in eight animals are shown in Fig. 4A and Table III. Inspection of the $(\mathrm{TF} / \mathrm{P})_{\mathrm{K}}$ ratios in the upper portion of Fig. 4A reveals values approximating unity in the proximal tubule. Considerable scatter is evident in the potassium concentration ratios in the distal tubule (range $=0.26$ 3.43 ), but the slope of the line indicates a significant rise along the tubule (Table V). When these ratios are factored by simultaneously determined TF/P inulin concentration ratios, ${ }^{8}$ net addition of potassium ( 0.13 rising to 0.26 ) is demonstrated (Fig. 4A, lower portion, and Table V). Although the $(U / P)_{K}$ ratio (Fig. $4 A$ ) rises to quite high levels, the ratio $\left[(U / P)_{K} /(U / P)_{I_{n}}\right]$

5 The $T F / P$ or $U / P$ ratio for sodium, factored by the corresponding $\mathrm{TF} / \mathrm{P}$ inulin ratio, gives the fraction of filtered sodium remaining at the puncture site (or final urine).

- Since potassium is not only reabsorbed, but also added to the tubule fluid, the TF/P (or $U / P$ ) ratio for this ion, factored by the simultaneously determined $T F / P$ inulin ratio, is defined as the amount of potassium relative to the amount filtered remaining at the puncture site. This relationship is intended merely to provide a convenient means of evaluating the fate of potassium in the tubule by taking into account the simultaneous reabsorption of water. 
TABLE V

Slopes of the Regression Lines Calculated from Data Obtained from the Distal Tubule of Hydropenic Monkeys*

\begin{tabular}{|c|c|c|c|c|c|c|}
\hline & $\begin{array}{c}\text { Transtubular } \\
\text { osmolality } \\
\text { ratio } \\
y=(\mathrm{TF} / \mathrm{P})_{\text {osm }}\end{array}$ & $\begin{array}{l}\text { liraction of } \\
\text { filtered water } \\
\text { remaining } \\
y=(P / T F)_{\mathbf{n}}\end{array}$ & $\begin{array}{l}\text { Transtubular } \\
\text { Na concen. } \\
\text { ratio } \\
y=(\mathrm{TF} / \mathrm{P})_{\mathrm{Na}}\end{array}$ & $\begin{array}{l}\begin{array}{c}\text { Fraction of } \\
\text { filtered sodium } \\
\text { remaining } \\
y=\frac{(\mathrm{TF} / \mathrm{P})_{\mathbf{N}}}{(\mathrm{TF} / \mathrm{P})_{I_{\mathrm{n}}}}\end{array}\end{array}$ & $\begin{array}{l}\text { Transtubular } \\
\text { K concen. } \\
\text { ratio } \\
y=(\mathrm{TF} / \mathrm{P})_{\mathrm{K}}\end{array}$ & $\begin{array}{c}\text { Fraction of } \\
\text { filtered potas- } \\
\text { sium remaining } \\
y=\frac{(\mathrm{TF} / \mathrm{P}) \mathbf{K}}{(\mathrm{TF} / \mathrm{P})_{\mathbf{n}}}\end{array}$ \\
\hline Slope & 0.00070 & -0.00249 & 0.00048 & -0.00332 & 0.0066 & 0.00485 \\
\hline SE & \pm 0.00102 & \pm 0.00095 & \pm 0.0017 & \pm 0.00225 & \pm 0.0025 & \pm 0.00219 \\
\hline No. observations & 28 & 33 & 30 & 28 & 30 & 28 \\
\hline$P$ value & 0.5 & $<0.025$ & $>0.5$ & $0.1<P<0.2$ & $<0.025$ & $<0.05$ \\
\hline
\end{tabular}

* These slopes are calculated from the relationship $\log y=a+b x$ where $y$ represents the value for each heading defined above, and $x$ represents the puncture site expressed as per cent of the total length of the distal convoluted tubule. A $P$ value of $<0.05$, by convention, indicates that the relationship is a significant one (i.e., there is greater than a $95 \%$ chance that the slope is different from zero).

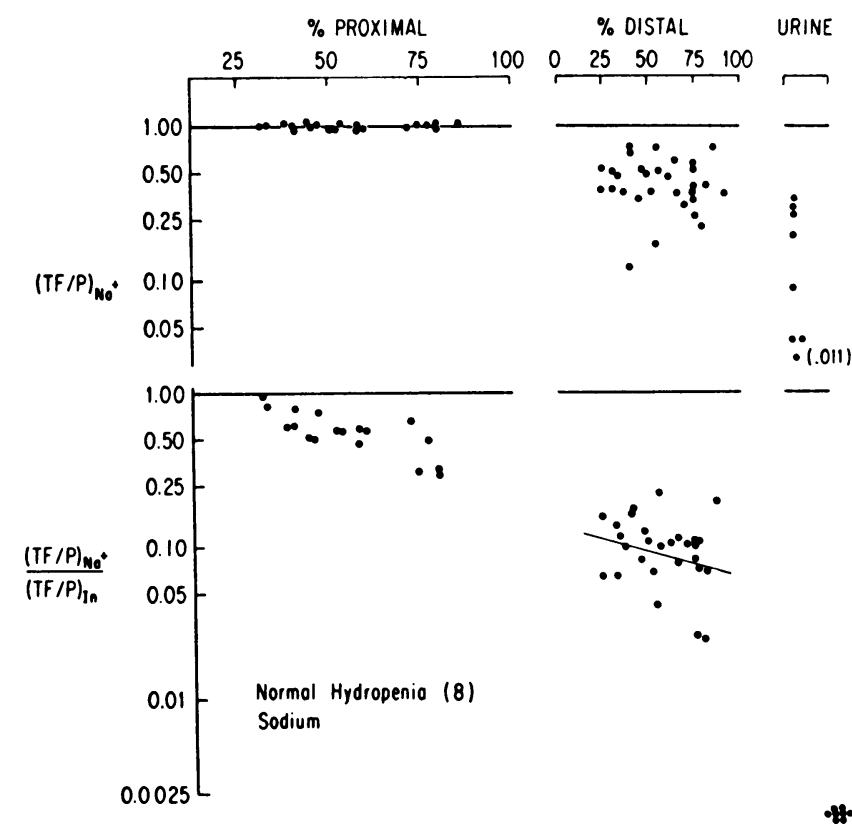

FigURE 3A Tubule fluid to plasma and urine to plasma sodium concentration ratios (upper) and sodium clearance ratios (lower) during hydropenia.

(Table I) does not increase above the mean value of this ratio in late distal tubule. To the extent that these surface convolutions of the distal tubule can be assumed to be representative of all distal tubules in the kidney, these data indicate that net potassium addition in the collecting ducts did not occur.

\section{Furosemide}

After the administration of this diuretic, urine flow increased promptly and in all instances reached maximal levels within $15 \mathrm{~min}$. Glomerular filtration rates (Table I) were similar to those obtained during control studies in hydropenic animals. Mean values for fractional water, sodium,

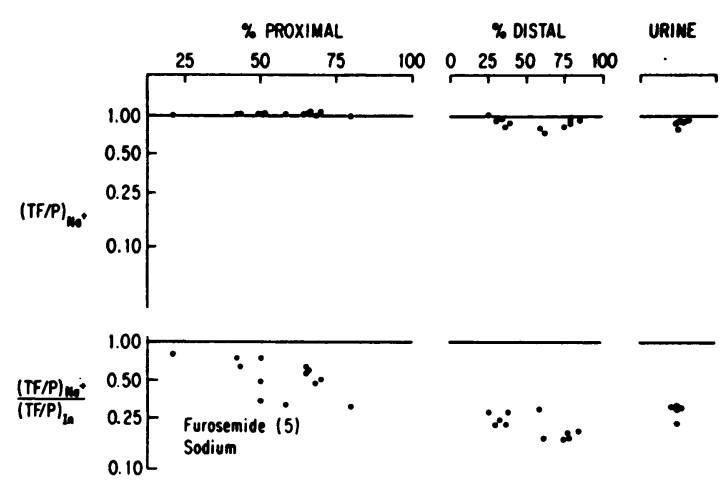

FIGURE $3 B \quad T F / P$ and $U / P$ sodium concentration ratios (upper) and sodium clearance ratios (lower) during furosemide diuresis. 


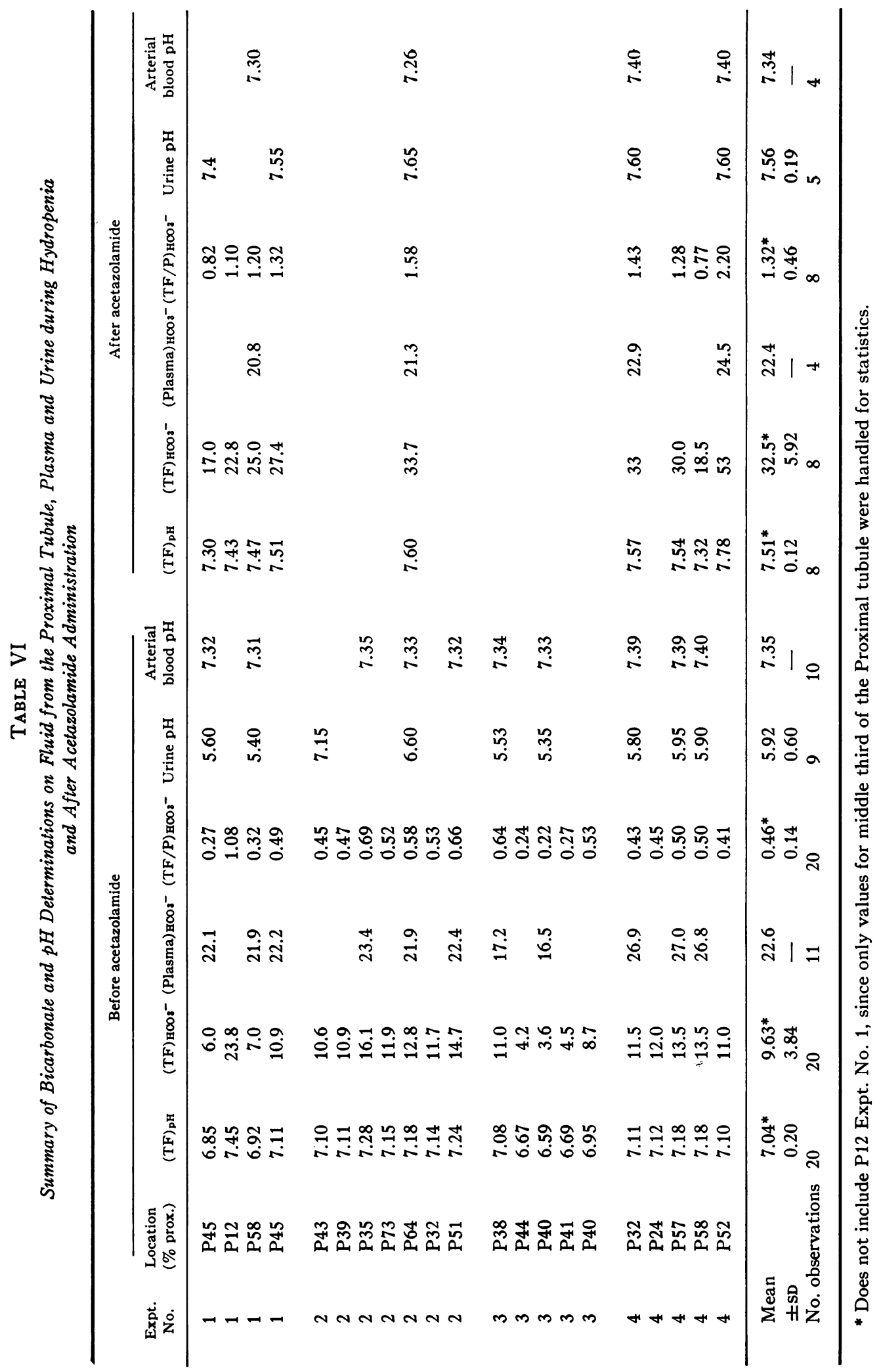


and potassium excretion in the urine after furosemide administration are compared to mean values in hydropenic animals in Table I. The fraction of filtered sodium and water excreted ranged from 18 to $36 \%$, and 24 to $42 \%$ respectively, whereas fractional potassium excretion ranged from 61 to $108 \%$. As shown in Fig. 1B, 3B, 4B, and Table III, proximal $\mathrm{TF} / \mathrm{P}$ osmolality and sodium and potassium concentration ratios were unchanged when compared to studies during antidiuresis. The slope of the line representing fractional water reabsorption in the proximal tubule $(-0.00667 \pm 0.00156 \mathrm{SE})$ was not significantly different from the value found during antidiuresis (Fig. 2B).

In contrast, events in the distal tubule were found to have changed markedly. Furosemide nearly abolished the distal transtubular osmotic and sodium concentration gradients (Fig. 1B, 3B, and Table IV). This increase in solute concentration was present in samples obtained from the early distal tubule, and further changes occurred neither along this segment nor in the collecting ducts [mean $(\mathrm{U} / \mathrm{P}){ }_{\text {osm }}=0.94 \pm 0.03 \mathrm{sD}$ ]. The fraction of filtered water $(\mathrm{P} / \mathrm{TF})_{\text {In }}$ remaining in the distal tubule was not significantly different from that found during antidiuresis (Table IV and Fig. $2 \mathrm{~B}$ ), indicating that fractional water reabsorption to this point was unaffected by furosemide. However, the fraction of filtered sodium in this segment was twice the value found in the control group (Fig. 3A and 3B). Further net sodium reabsorption in the distal tubule or collecting ducts was not detected. Although it appears from Fig. 2B that water reabsorption occurred in the distal tubule, it is not possible to state this occurrence with certainty, since most of the samples obtained from early sites were from one animal. After furosemide administration, little additional water reabsorption occurred in collecting ducts (Fig. 2A, 2B, and Table I).

After furosemide administration, all $(\mathrm{TF} / \mathrm{P})_{\mathbf{K}}$ concentration ratios in the distal tubule were equal to or greater than unity (range $=0.98-3.43$ ), as shown in Fig. 4B upper portion. The amount of potassium present in the distal tubule relative to the amount filtered was considerably greater in the furosemide-treated animals (Fig. 4B, lower portion). Although it appears from Fig. 4B that there was no net addition of potassium in the

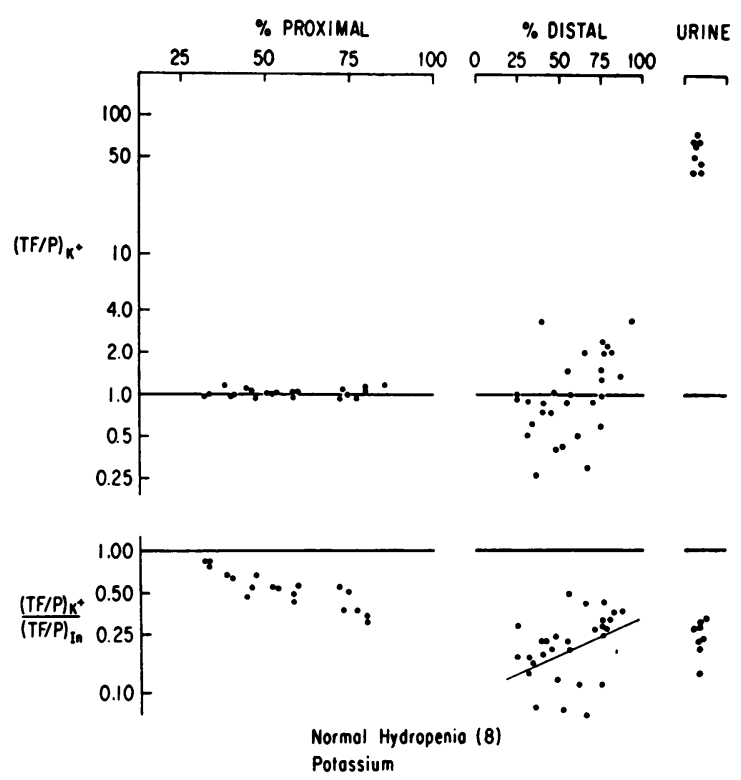

Figure 4A Tubule fluid to plasma and urine to plasma potassium concentration ratios (upper) and potassium clearance ratios (lower) during hydropenia.

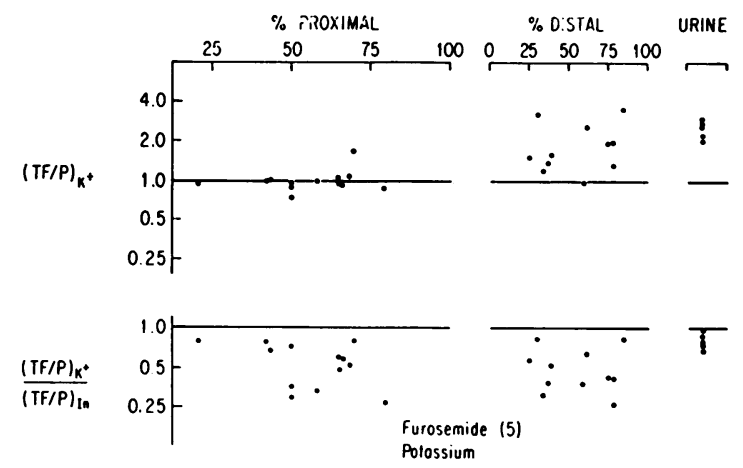

Figure $4 B \quad T F / P$ and $U / P$ potassium concentration ratios (upper) and potassium clcarance ratios (lower) during furosemide diuresis.

distal tubule, it should be remembered that the samples from the early and late portions of the distal tubule were not from the same animals. Similarly it is not possible to be certain of the fate of potassium in the collecting ducts, because of the scatter in the data.

Bicarbonate reabsorption. In Table VI and Fig. 5 are summarized the results obtained in four experiments, in which the TF/P bicarbonate concentration ratios were calculated from the $\mathrm{pH}$ of tubule fluid determined with quinhydrone electrodes before and after administration of acetazolamide. 


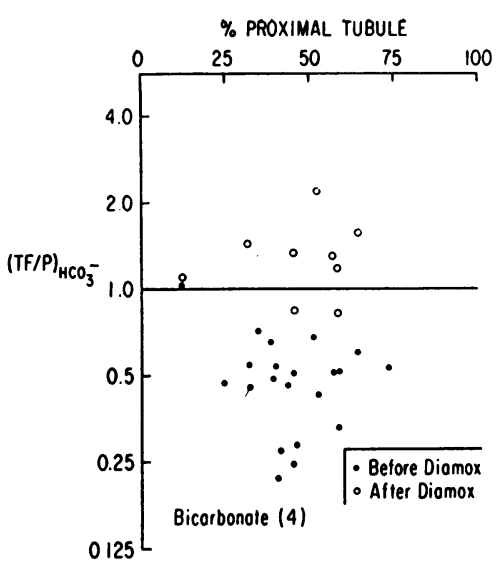

Figure 5 Tubule fluid to plasma bicarbonate concentration ratios. After diamox, samples of tubule fluid were obtained by the recollection technique.

Plasma $\mathrm{HCO}_{3}$ concentrations and $\mathrm{pH}$ were relatively stable throughout each experiment and changed only slightly after acetazolamide administration. Note that in Experiment 3 the plasma $\mathrm{HCO}_{3}$ concentrations were low, but the (TF/ $\mathrm{P})_{\mathrm{HCO}_{3}}$ ratios were not obviously different from values obtained in the other experiments. The bicarbonate concentrations and $\mathrm{pH}$ of all samples of fluid obtained from the middle third of the proximal tubule prior to acetazolamide administration were significantly lower than those in plasma. From these data we were unable to detect a progressive decline in $(\mathrm{TF} / \mathrm{P})_{\mathrm{HCO}_{3}}$ along the course of the proximal tubule. However, it can be seen that the only early proximal sample (P 12\%) had a bicarbonate concentration almost identical with the concentration in plasma. After an intravenous injection of acetazolamide, nine recollection samples from three animals revealed a uniform increase in $(\mathrm{TF} / \mathrm{P})_{\mathrm{HCO}_{3}}$. In all but two instances, the bicarbonate concentration in tubule fluid exceeded the concentration in plasma.

\section{DISCUSSION}

The study of nephron function in the rhesus monkey by use of the micropuncture technique offers several advantages over similar studies in rodents and dogs. One important advantage is that in extending these data to an understanding of renal function in man, phylogenetic differences are less formidable. Moreover, the short loop of Henle and the arrangement of the proximal and distal convolutions on the surface of the kidney make almost the entire nephron, up to the collecting duct, accessible to micropuncture. Finally, the monkey is more suitable than other animals for study of the mechanism and site of action of diuretic drugs, particularly with respect to changes in function of the distal tubule. The rat is much less responsive to diuretics than man and has been unsatisfactory to study for this reason.

Fractional water reabsorption in the proximal tubule of the antidiuretic monkey is similar to values reported for the dog and rat from this and other laboratories $(1,16,17)$. In earlier studies in rat (18-20) and $\operatorname{dog}(21,22)$, variable but greater fractional water reabsorption in the proximal tubule was found than in the monkey. This fact may be attributable to differences in the physiological state of the animals, particularly in the extracellular fluid volume. The fraction of filtered water arriving in the early distal tubule of the monkey is similar to the fraction found in the $\operatorname{dog}(1)$. The values reported for the rat $(20$, 23) are somewhat lower than in the dog and monkey, but again may reflect the physiological state of the animals studied. In the rat, fluid from the early distal tubule is hypotonic and during antidiuresis becomes isotonic to plasma in the midportion (24). During this osmotic equilibration, nearly three-fourths of the volume is reabsorbed $(19,20)$. The remaining fraction of filtered water $(8-10 \%)$ enters the collecting ducts where it is almost completely reabsorbed (2). In the antidiuretic monkey, as in the dog (25), fluid remains hypotonic to plasma throughout the distal tubule. Despite this considerable driving force for passive water reabsorption, only about one-third of the volume is reabsorbed. Thus, as in the dog, a larger fraction of the glomerular filtrate enters the collecting ducts of the monkey than enters the collecting ducts of the rat (1).

The reabsorption of sodium in hypertonic proportions in the loop of Henle is evidence that the primate nephron has the potential to generate the "single effect," the process fundamental to the countercurrent mechanism for urine concentration (26). However, it should be remembered that cortical nephrons, such as those studied here, do not contribute to the concentrating mechanism. The fraction of filtered sodium reaching the distal tubule of the monkey is similar to values reported for the dog (1). In neither species could further 
net sodium reabsorption in the distal tubule be detected, presumably because of the low permeability to water and the presence of a limiting concentration gradient for sodium (1). As in the rat, the site of the steepest transtubular concentration gradient for sodium is in the collecting duct, not the distal tubule (2).

On the basis of clearance data (27) it has been shown that in the dog, furosemide administration in doses of $0.5-5.0 \mathrm{mg} / \mathrm{kg}$ impairs free water excretion and reduces free water reabsorption under appropriate experimental conditions. Since the ascending limb of Henle's loop is the only, site in the nephron where sodium reabsorption participates in the formation of both dilute and concentrated urine, it has been concluded that the principal site of action of this drug is in this segment. In the same study the authors infer from the magnitude of the diuresis (up to $38 \%$ of filtered sodium) that reabsorption in the proximal tubile was also inhibited. In a micropuncture study in rats, Deetjen (28) found an inhibitory effect of furosemide on reabsorption of fluid in the proximal tubule when GFR was reduced by about $50 \%$, but he could not detect an inhibitory effect when GFR remained in the normal range. In another micropuncture study, Dirks, Cirksena and Berliner (29), using the recollection micropuncture technique, were unable to detect an action of this drug in the proximal tubules in dogs. Rector and his associates (16), using both stopped-flow and freeflow micropuncture techniques in the rat, found that although furosemide inhibited intrinsic reabsorptive capacity by about $40 \%$, the drug had no effect on fractional reabsorption in the proximal tubule. The failure to detect a decrease in fractional reabsorption was thought to be due to a disproportionate rise in the volume of the tubule relative to the filtration rate, as evidenced by the prolonged transit time observed after administration of the drug. In the present study, furosemide administration in doses comparable to those used in previous experiments resulted in the prompt excretion of up to $36 \%$ of the filtered sodium and up to $42 \%$ of the filtered water. Despite this massive diuresis, fractional reabsorption in the proximal tubule was not depressed. Since the filtration rate was also unchanged, the absolute rate of sodium reabsorption in the proximal tubule was similar to control values. The fraction of filtered water reach- ing the accessible portion of the distal tubule did not differ from the control value. However, fractional delivery of sodium to the distal tubule after furosemide administration was twice that found in controls, indicating that the inhibition of sodium reabsorption produced by this drug occurred at a site or sites beyond the water permeable portion of the nephron, i.e., beyond the descending limb of Henle's loop.

The interpretation of the $\mathrm{TF} / \mathrm{P}$ ratio for potassium depends on a consideration of the electrical potential. A recent study of the electrical potential in the rat nephron by Frömter and Hegel led them to the conclusion that there is no electrical potential difference between the proximal tubule lumen and the surrounding interstitial fluid (30). Their primary observations were essentially identical with those obtained by other workers who have measured the electrical potentials in the proximal convoluted tubules of rats $(2,31,32)$ and dogs (33). When the tubule is first punctured a negative deflection is encountered; in a large number of studies, these negative deflections have always varied rather widely but have generally averaged close to $20 \mathrm{mv}$, tip of the exploring electrode negative. This potential may be maintained for a period varying from a few seconds to several minutes, generally shorter in the dog than in the rat, and then drops to zero. Most investigators have assumed that the $20 \mathrm{mv}$ value represents the true transtubular potential, and that the drop to zero is the result of short-circuiting through the puncture hole. However, Frömter and Hegel found that the potential difference remained at zero even when the tip of the exploring electrode was thrust down the lumen far enough so that any electrical leak at the puncture site should have had little effect on the observed transtubular potential. They concluded that the zero value was the true value, and that the substantial negative value initially observed is derived from some intracellular location, presumably the brush border.

Since all previous observers have found both the $20 \mathrm{mv}$ and the zero potentials, it has seemed to us unprofitable to explore the problem with additional similar measurements. The problem is one of choosing which of the two populations represents the true transtubular electrical potential. In a recent extensive series of measurements in the dog (1) and in the present study in the monkey, the 
potassium concentration in the lumen of the proximal tubule has been found to be very nearly identical with the concentration in plasma, with only small variations in the mean value. This fact leads us to extend the conclusion of Frömter and Hegel to the dog and monkey, to infer that there is probably no significant transtubular electrical potential difference, and further to infer that the reabsorption of potassium in the proximal convoluted tubule is probably passive, with the potassium ion close to diffusion equilibrium across the tubule wall. These conclusions derive from the fact that if there were an electrical potential gradient and if potassium were passively distributed, the concentration ratio would not be one. On the other hand, if there were active transport of potassium, with or without an electrical potential difference, the concentration ratio of one would not be more likely than any other value. ${ }^{7}$ We therefore believe that the observations are most easily explained if it is assumed that there is neither an electrical gradient nor active transport of potassium in the proximal convoluted tubule.

The conclusion that potassium reabsorption in the proximal convoluted tubule is passive is at variance with the conclusions of several previous studies in which $T F / P$ potassium concentration ratios significantly above and below one were found (and in which a significant transtubular electrical potential was assumed) (31-35). We are unable to explain the difference between the concentration ratios found in this study and previous studies. However, we are confident that the analytical procedure used in the present study is considerably more reliable than that used in the earlier study in the dog (34) and probably that used in most of the others as well.

A $(T F / P)_{x}$ less than unity in the proximal tubule has been found in the presence of a high concentration of a poorly reabsorbable solute, such as during the administration of mannitol $(2,35)$, or during microperfusion of the tubule with iso-

7 This argument does not apply to the concentration of sodium. The concentration of sodium in the lumen must remain close to the concentration in plasma so long as sodium salts constitute all but a minor part of the solute in the lumen and the fluid in the lumen has the same osmolality as the plasma. Potassium contributes so little to the osmolality of proximal tubule fluid that its concentration can vary independently of the osmolality. tonic raffinose solution $(34,36)$. However, those data do not add to the evidence for an active process for reabsorption of potassium, since the same investigators found similarly low $(\mathrm{TF} / \mathrm{P})_{\mathbf{K}}$ ratios in the proximal tubule in the absence of a poorly reabsorbable solute, (i.e., in free-flow collections during hydropenia).

About one-eighth of the amount of potassium filtered appeared at the earliest accessible portion of the distal tubule of the monkey. It cannot be resolved whether this potassium represents a portion of the original amount filtered or potassium newly added by the inaccessible loop and early distal tubule. Net addition of an amount of potassium equal to that initially present in the distal tubule was found in this study; no further addition was found to cccur in the collecting ducts. Similar observations have been reported in the rat (2). If the electrical potential in the distal tubule of the monkey is negative with respect to peritubular fluids, as it is in the rat, then the observation that the $(T F / P)_{K}$ in the early distal tubule is less than one indicates, by the usual criteria, active reabsorption of this ion at or just before this site. Furosemide appeared to inhibit this reabsorption. Similar results have recently been reported for the dog (1).

The reabsorption of bicarbonate in the proximal tubule of the rhesus monkey is nearly complete, a finding similar to that in the dog and rat $(21,37)$. The $\mathrm{pH}$ of tubule fluid in quinhydrone microelectrodes was measured at a time when the bicarbonate was in equilibrium with carbon dioxide at a tension approximately equal to that found in extracellular fluids. If a similar equilibrium exists in the lumen of the proximal tubule, as has been suggested by Rector and his associates (38), then the $\mathrm{pH}$ recorded in these experiments in vitro (7.04) will be approximately equal to the true $\mathrm{pH}$ in vivo. This degree of acidification of proximal fluid is similar in the rat (37), and considerably more than has been found recently in the dog under similar experimental conditions (39). After administration of acetazolamide, the bicarbonate concentration in the tubule fluid rose, often to a value exceeding the concentration in plasma. This indicates that reabsorption of this ion was inhibited to a greater degree than the reabsorption of sodium and water. 


\section{REFERENCES}

1. Bennett, C. M., J. R. Clapp, and R. W. Berliner. 1967. Micropuncture study of the proximal and distal tubule in the dog. Am. J. Physiol. 213: 1254.

2. Malnic, G., R. M. Klose, and G. Giebisch. 1966. Micropuncture study of distal tubular potassium and sodium transport in rat nephron. Am. J. Physiol. 211: 529.

3. Orloff, J. 1966. Pitfalls in the use of stop-flow for the localization of diuretic action, with special reference to Na reabsorption. Ann. N.Y. Acad. Sci. 139: 344.

4. Vurek, G. G., C. M. Bennett, R. L. Jamison, and J. L. Troy. 1967. An air-driven micropipette sharpener. J. Appl. Physiol. 22: 191.

5. Ramsay, J. A., and R. H. J. Brown. 1955. Simplified apparatus and procedure for freezing point determinations upon small volumes of fluid. J. Sci. Instr. 32: 372.

6. Vurek, G. G. and R. L. Bowman. 1965. Helium-glow photometer for picomole analysis of alkali metals. Science. 149: 448.

7. Vurek, G. G., and S. E. Pegram. 1966. Fluorometric method for the determination of nanogram quantities of inulin. Anal. Biochem. 16: 409.

8. Führ, J., J. Kaczmarczyk, and C. D. Krüttgen. 1955. Eine einfache colorimetrische Methode zur Inulin bestimmung für Nierenclearanceuntersuchungen bei Stoffwechselgesunden und Diabetikern. Klin. Wochschr. 33: 729.

9. Pierce, J. A., and H. Montgomery. 1935. A microquinhydrone electrode: its application to the determination of $\mathrm{pH}$ of glomerular urine of Necturus. J. Biol. Chem. 110: 763.

10. Sweet, A. Y., M. F. Levitt, and H. L. Hodes. 1961. Kidney function, body fluid compartments, and water and electrolyte metabolism in the monkey. Am. J. Physiol. 201: 975.

11. Walker, A. M., and J. Oliver. 1941. Methods for the collection of fluid from single glomeruli and tubules of the mammalian kidney. Am J. Physiol. 134: 562.

12. Sperber, I. 1944. Studies on the mammalian kidney. Zool. Bidr. Upps. 22: 249.

13. Watson, J. F. 1966. Potassium reabsorption in the proximal tubule of the dog nephron. J. Clin. Invest. 45: 1341.

14. Pai, H. C. 1935. Dissections of nephrons from the human kidney. J. Anat. Soc. India. 69: 344.

15. Snedecor, G. W. 1956. Statistical methods applied to experiments in agriculture and biology. State College Press, Ames. 5th edition. 122.

16. Rector, F. C., Jr., J. C. Sellman, M. Martinez-Maldonado, and D. W. Seldin. 1967. The mechanism of suppression of proximal tubular reabsorption by saline infusions. J. Clin. Invest. 46: 47.

17. Landwehr, D., J. Schnermann, R. M. Klose, and G. Giebisch. 1967. The effect of acute reduction in glomerular filtration rate on renal tubular sodium and water reabsorption. Federation Proc. 26: 547. (Abstr.)
18. Glabman, S., H. S. Aynedjian, and N. Bank. 1965. Micropuncture study of the effect of acute reductions in glomerular filtration rate on sodium and water reabsorption by the proximal tubules of the rat. J. Clin. Invest. 44: 1410.

19. Lassiter, W. E., C. W. Gottschalk, and M. Mylle. 1961. Micropuncture study of net transtubular movement of water and urea in nondiuretic mammalian kidney. Am. J. Phy'siol. 200: 1139.

20. Giebisch, G., R. M. Klose, and E. E. Windhager. 1964. Micropuncture study of hypertonic sodium chloride loading in the rat. Am. J. Phy'siol. 206: 687.

21. Clapp, J. R., J. F. Watson, and R. W. Berliner. 1963. Osmolality, bicarbonate concentration, and water reabsorption in proximal tubule of the dog nephron. $\mathrm{Am}$. J. Physiol. 205: 273.

22. Watson, J. F. 1966. Effect of saline loading on sodium reabsorption in the dog proximal tubule. $\mathrm{Am}$. J. Physiol. 210: 781.

23. Cortney, M. A., M. Mylle, W. E. Lassiter, and C. W. Gottschalk. 1965. Renal tubular transport of water, solute, and $\mathrm{PAH}$ in rats loaded with isotonic saline. Am. J. Physiol. 209: 1199.

24. Gottschalk, C. W., and M. Mylle. 1959. Micropuncture study of the mammalian urinary concentrating mechanism: evidence for the countercurrent hypothesis. An. J. Physiol. 196: 927.

25. Clapp, J. R., and R. R. Robinson. 1966. Osmolality of distal tubular fluid in the dog. J. Clin. Invest. 45: 1847.

26. Gottschalk, C. W. 1964. Osmotic concentration and dilution of the urine. Am. J. Med. 36: 670 .

27. Suki, W., F. C. Rector, Jr., and D. W. Seldin. 1965. The site of action of furosemide and other sulfonamide diuretics in the dog. J. Clin. Invest. 44: 1458.

28. Deetjen, P. 1965. Mikropunktionsuntersuchungen zur Wirkung von Furosemid. Arch. Ges. Physiol. 284: 184.

29. Dirks, J. H., W. J. Cirksena, and R. W. Berliner. 1966. Micropuncture study of the effect of various diuretics on sodium reabsorption by the proximal tubules of the dog. J. Clin. Invest. 45: 1875.

30. Frömter, E., and U. Hegel. 1966. Transtubular Potentialdifferenzen an proximalen und distalen Tubuli der Rattenniere. Arch. Ges. Physiol. 291 : 107.

31. Bloomer, H. A., F. C. Rector, Jr., and D. W. Seldin. 1963. The mechanism of potassium reabsorption in the proximal tubule of the rat. J. Clin. Invest. 42: 277.

32. Malnic, G., R. M. Klose, and G. Giebisch. 1964. Micropuncture study of renal potassium excretion in the rat. Am. J. Physiol. 206: 674.

33. Watson, J. F., J. R. Clapp, and R. W. Berliner. 1964. Micropuncture study of potassium concentration in proximal tubule of dog, rat and Necturus. J. Clin. Invest. 43: 595.

34. Marsh, D. J., K. J. Ullrich, and G. Rumrich. 1963. Micropuncture analysis of the behavior of potassium ions in rat renal cortical tubules. Arch. Ges. Physiol. 277: 107 . 
35. Rector, F. C., Jr., H. A. Bloomer, and D. W. Seldin. 1964. Proximal tubular reabsorption of potassium during mannitol diuresis in rats. J. Lab. Clin. Med. 63: 100.

36. Malnic, G., R. M. Klose, and G. Giebisch. 1966. Microperfusion study of distal tubular potassium and sodium transfer in rat kidney. Am. J. Physiol. 211: 548.

37. Rector, F. C., Jr., H. A. Bloomer, and D. W. Seldin. 1964. Effect of potassium deficiency on the reabsorp- tion of bicarbonate in the proximal tubule of the rat kidney. J. Clin. Invest. 43: 1976.

38. Rector, F. C., Jr., N. W. Carter, and D. W. Seldin. 1965. The mechanism of bicarbonate reabsorption in the proximal and distal tubules of the kidney. $J$. Clin. Invest. $44: 278$.

39. Bernstein, B. A., and J. R. Clapp. Micropuncture study of bicarbonate reabsorption by the dog nephron. Am. J. Phy'siol. In press. 